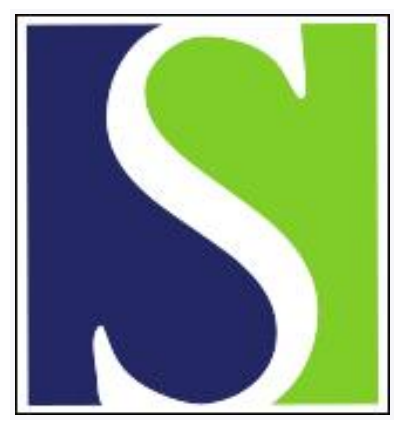

Scand J Work Environ Health 2008;34(3):206-212

https://doi.org/10.5271/sjweh.1230

Issue date: 30 Jun 2008

Cardiovascular risk factors and primary selection into shift work

by Nabe-Nielsen K, Garde AH, Tüchsen F, Hogh A, Diderichsen F

Affiliation: The National Research Centre for the Working Environment, Lerso Parkallé 105, DK-2100 Copenhagen, Denmark. knn@nrcwe.dk

Refers to the following texts of the Journal: 1999;25(2):85-99 2006;32(3):204-208 2001;27(2):97-105 2004;30(2):149-156

The following articles refer to this text: 2008;34(6):483-486; 2009;35(1):48-55; 2009;35(3):163-179; 2009;35(3):157-161; 2009;35(4):309-318; 2009;35(5):361-367; 2010;36(6):515-516; 2015;41(1):84-93; 2015;41(3):259-267; 2017;43(6):569-577; 2018;44(4):385-393; 2020;46(4):350-355; 2022;48(1):31-40; 2022;48(3):200-209

Key terms: cardiovascular risk factor; evening work; follow-up; health care worker; night work; obesity; primary selection; shift work; smoking; social worker

This article in PubMed: www.ncbi.nlm.nih.gov/pubmed/18728910 


\title{
Cardiovascular risk factors and primary selection into shift work
}

\author{
by Kirsten Nabe-Nielsen, MSc, ${ }^{1}$ Anne Helene Garde, PhD, ${ }^{1}$ Finn Tüchsen, MSc, ${ }^{1}$ Annie Hogh, PhD, ${ }^{1}$ Finn \\ Diderichsen, DrMedSc²
}

\begin{abstract}
Nabe-Nielsen K, Garde AH, Tüchsen F, Hogh A, Diderichsen F. Cardiovascular risk factors and primary selection into shift work. Scand J Work Environ Health. 2008;34(3):206-212.
\end{abstract}

\begin{abstract}
Objectives This study examined differences between future shift workers and future day workers as regards cardiovascular risk factors before they began different work schedules and the differences that remained after control for sociodemographic factors and general self-efficacy.

Methods Altogether 2870 newly educated social and health care workers filled out a questionnaire a few weeks before finishing their formal training and again 1 year after graduation. They answered questions on diabetes, hypertension, lifestyle habits, sociodemographic factors, and general self-efficacy.

Results In the unadjusted analyses, baseline obesity was associated with fixed evening work at follow-up. Minimal or light-to-moderate leisure-time physical activity was associated with a decrease in the odds ratio (OR) for two or three shifts including night work. Smoking status was associated with fixed evening work, fixed night work, and two- or three- shift work including night work. After adjustment for sociodemographic factors and general self-efficacy, smoking was prospectively associated with fixed evening work [OR $1.56,95 \%$ confidence interval (95\% CI) 1.21-2.02] and fixed night work (OR 1.64, 95\% CI 1.04-2.56). Being an ex-smoker was associated with two- or three-shift work including night work (OR 1.85, 95\% CI 1.28-2.68). The association between two- and three-shift work and smoking was only of borderline significance (OR 1.37, 95\% CI 1.00-1.87).

Conclusions Compared with future day workers, fixed evening or fixed night workers already smoked more before they began shift work. Being an ex-smoker was significantly associated with two- or three-shift work including night work. These results indicate that smoking status should not solely be treated as a mediator between some variants of shiftwork schedules and cardiovascular diseases but should also be considered a confounder.
\end{abstract}

Key terms evening work; follow-up; health care worker; night work; obesity; smoking; social worker.

Shift work-defined as work outside normal day workhours (1) - has been found to be associated with an increased risk of cardiovascular diseases (CVD) (2-6). However, even though the association between shift work and CVD has been studied for half a century, the results are inconsistent (7), and even the newest studies of the role of shift work in the etiology of CVD come to different conclusions $(8,9)$. Selection into and out of shift work may, to some extent, explain these differences. It has been shown that secondary selection out of shift work is a major pitfall in shiftwork research (10). On the other hand, in their study of selection out of shift work due to cardiovascular risk factors, Kivimäki et al (11) found no evidence of a selection bias that could lead to biased estimates of the association between shift work and CVD.
It has been suggested that the pathway between shift work and CVD partially proceeds through behavioral changes caused by shift work (12). Results from earlier studies-most often among men-show that several major cardiovascular risk factors [smoking (4, 13-15), hypertension (16), diabetes (17), and high cholesterol concentration (18)] are more prevalent among shift workers than among day workers. The differences between day workers and shift workers could be caused by behavioral changes as a consequence of work schedule. For example, one prospective follow-up study showed that the number of cigarettes smoked per day (among the smokers) increased more among the shift workers than among the day workers (19). In another study, shift workers had an increased risk of starting to smoke during a 2 year follow-up (20). Thus smoking could be

1 The National Research Centre for the Working Environment, Copenhagen, Denmark.

2 Department of Social Medicine, Institute of Public Health, University of Copenhagen, Copenhagen, Denmark.

Correspondence to: Kirsten Nabe-Nielsen, The National Research Centre for the Working Environment, Lerso Parkallé 105, DK-2100 Copenhagen, Denmark. [knn@nrcwe.dk] 
a mediating factor between shift work and CVD. Differences could also be present already before either day or shift work is begun and thus be a result of primary selection into shift work. This possibility may lead to biased estimates of the risk of disease attributable to shift work.

Although selection into shift work is widely recognized as a methodological obstacle $(2,11,19,21,22)$, only few studies have tried to assess the magnitude of this bias. Knutsson \& Åkerstedt (23) found that, among 53 men applying for blue-collar jobs, future shift workers did not differ from future day workers in terms of previous illnesses, current symptoms, or cardiovascular risk factors (body mass index, blood pressure, serum cholesterol, serum triglycerides, and smoking). In turn, future shift workers were younger, more-pronounced evening types, and had a less rigid sleep pattern than future day workers (23). These findings are in contrast to the results from a more recent cohort study of 239 recently employed shift workers and 157 recently employed day workers. In this study, the baseline measures demonstrated that, compared with day workers, shift workers had a higher body mass index, a higher waist-tohip ratio, and a higher percentage of the daily energy intake coming from fat and that they were more frequently smokers (19). Thus, regarding sleeping pattern, weight, diet, and smoking habits, a difference between future day and shift workers cannot be ruled out. We therefore hypothesized that selection mechanisms play a role when a person applies for shift work. Moreover, studies by Knusson \& Åkerstedt (23) and van Amelsvoort et al (19) also showed that future day and shift workers may differ in regard to age, gender, and education. It is therefore possible that sociodemographic factors could act as confounders and thereby explain some of the differences in cardiovascular risk factors between day and shift workers. Personal resources could also confound the association between cardiovascular risk factors and work schedule. One such personality resource could be general self-efficacy, which refers to a person's confidence that he or she can successfully perform a course of behaviors in a given situation (24). Self-efficacy has been shown to influence lifestyle changes (25), and variants of self-efficacy have also been focused on in studies of the determinants of occupational choices $(26,27)$; one such occupational choice could be workhours and their implications as regards social contact and worktasks.

Our present follow-up study gives a unique opportunity to study primary selection into shift work among social and health care helpers and assistants who left social and health care education for their first job in the eldercare sector after finishing their formal training. The aim of the study was therefore to examine whether future shift workers differed from future day workers with respect to cardiovascular risk factors already before beginning different work schedules and to investigate whether differences remained after control for sociodemographic factors and general self-efficacy.

\section{Study population and methods}

\section{Study population}

Our study was designed as a prospective cohort study of all Danish social and health care helpers and assistants who finished their education in 2004. Social and health care helpers have 14 months of training and are qualified for work with nursing and practical assistance in the eldercare sector. Education as a social and health care assistant builds on the education for a social and health care helper and requires another 20 months of training. The social and health care assistants are qualified for work in eldercare, as well as in hospitals. The study consisted of a baseline questionnaire survey a few weeks before the students finished their education and a follow-up questionnaire survey 1 year later. The study population consisted of 6347 students from 27 of the 28 Danish schools educating social and health care helpers and assistants. A total of 5696 persons (90\%) returned the baseline questionnaire. One year later, the follow-up questionnaire was mailed to all of the baseline respondents and was returned by 3708 persons (65\%). Only the 2870 persons who filled out both questionnaires and were employed in the eldercare or hospital sector at follow-up were included in the analyses. Of these participants, $95 \%$ were women, $62 \%$ were educated as a social and health care helper, $38 \%$ were educated as a social and health care assistant, and the mean age was 35 (SD 10.6) years in the baseline survey. The mean seniority in eldercare 1 year after the workers' formal education had been completed was 11.4 (SD 2.9) months. We included the following variables in the study: work schedule, cardiovascular risk factors, and covariates.

\section{Work schedule}

In the follow-up questionnaire, the participants were asked about which time of the day they usually worked. The response categories were fixed day work $(\mathrm{N}=1483)$, fixed evening work $(\mathrm{N}=482)$, fixed night work $(\mathrm{N}=124)$, alternating day and evening workhours $(\mathrm{N}=474)$, alternating evening and night workhours $(\mathrm{N}=34)$, and alternating day, evening and night workhours $(\mathrm{N}=273)$. The two latter groups were collapsed into one in the statistical analyses.

\section{Cardiovascular risk factors}

In the baseline questionnaire, the students were asked if they had diabetes or hypertension (response categories: 
yes or no). They were also asked if they were smokers, ex-smokers, or nonsmokers and were requested to give their height and weight [for the estimation of body mass index (BMI)], level of physical activity during leisure time [four response categories each accompanied by examples: almost physically inactive (eg, reading, watching television), light physical activity $2-4$ hours/week (eg, walking, bicycling, gardening), moderate physical activity 2-4 hours/week or light physical activity more than 4 hours/week (eg, vigorous walking, physical exercises implying sweating and breathlessness), moderate physical activity more than 4 hours/week or regular vigorous physical exercise (eg, competitions)], and consumption of fruit and vegetables (times per day).

\section{Covariates}

The covariates included in this study were gender, age, cohabitation status (whether they were living alone or together with parents or partner, and if they had children living at home), former experience from work in the eldercare sector, years of school attendance, and the father's occupation when the participant was 14 years old as a proxy measure of childhood socioeconomic status. The questionnaire also contained a 7-item general self-efficacy scale from the Copenhagen psychosocial questionnaire (COPSOQ). In the COPSOQ, the self-efficacy scale was reduced from the original 10 items to 7 items based on validation analyses that showed high correlations between several items that indicated that some items could be successfully omitted. The selfefficacy scale contained the following items: (i) I can always manage to solve difficult problems if I try hard enough, (ii) if someone opposes me, I can find the ways and means to get what I want, (iii) I am certain that I can accomplish my goals, (iv) thanks to my resourcefulness, I can handle unforeseen situations, (v) I can remain calm when facing difficulties because I can rely on my coping abilities, (vi) when I am confronted with a problem, I can find several solutions, (vii) I can handle whatever comes my way. The response categories were "not at all true", "barely true", "moderately true", and "exactly true" which were scored from 0-100 with 100 representing the highest degree of self-efficacy.

In table 1 the distribution of cardiovascular risk factors and the covariates are presented. In this study 51.7\% were fixed day workers, $16.8 \%$ were fixed evening workers, $4.3 \%$ were fixed night workers, $16.5 \%$ worked two shifts without night work, and finally $10.7 \%$ worked two or three shifts including night work.

In the cohort study of social and health care helpers and assistants, $35 \%$ of the study population dropped out between the baseline and follow-up. Hence, we conducted attrition analyses and found that the following variables were significantly associated with an increased risk of dropout from the study: reporting diabetes [odds ratio $(\mathrm{OR}) 1.39,95 \%$ confidence interval $(95 \% \mathrm{CI})$ 1.03-1.87], being a smoker (OR 1.29, 95\% CI 1.141.45), and low intake of fruit and vegetables (OR 1.30, 95\% CI 1.14-1.47). On the other hand, reporting hypertension and light leisure-time physical activity, as compared with high physical activity, were associated with a decrease in the risk of dropout (OR $0.75,95 \%$ CI 0.58-0.97, and OR 0.78, 95\% CI 0.62-0.99, respectively).

\section{Statistical analyses}

SPSS statistical software version 15.0 for Windows ${ }^{\circledR}$ (SPSS, Chicago, IL, USA) was used. We used a multinomial logistic regression to analyze the association between each cardiovascular risk factor and shift work, and, in the adjusted analyses, we controlled for sociodemographic factors and general self-efficacy. A multinomial logistic regression was used since the outcome had more than two main categories. In this study, we analyzed the odds of working fixed evenings, fixed nights, two shifts without night work, or two or three shifts with night work compared with the odds of working fixed day work in different exposure groups. A binary logistic regression was used for the attrition analyses when the risk factors for dropout from the study were investigated. A multinomial logistic regression is an alternative to a series of binary logistic regression models with the different types of shiftwork schedules compared with day work as dichotomous outcomes. A multinomial logistic regression assumes that the observations of each person should be independent of the observations of other persons, but contains no assumptions about the distribution of the outcome variables and no assumption about the proportional odds.

\section{Results}

In table 2 the unadjusted and adjusted estimates are presented for the associations between the selfreported cardiovascular risk factors at baseline and different types of shift work at follow-up. In the unadjusted analyses, obesity was associated with fixed evening work at follow-up. Being physically inactive during leisure time or being only lightly to moderately physically active was associated with a decrease in the odds ratio of two or three shifts including night work. Being a smoker was associated with fixed evening work, fixed night work, and two- or three-shift work including night work, and also being an ex-smoker was significantly associated with the latter type of work schedule at follow-up. 
Table 1. Baseline distribution of general self-efficacy and sociodemographic and cardiovascular risk factors among future day and shift workers. Prevalences and means are presented. (BMI = body mass index)

\begin{tabular}{|c|c|c|c|c|c|c|c|c|c|c|c|c|c|c|c|c|c|c|}
\hline \multirow[t]{2}{*}{ Characteristic } & \multicolumn{3}{|c|}{$\begin{array}{c}\text { Day work } \\
(\mathrm{N}=1483) \\
(51.7 \%)\end{array}$} & \multicolumn{3}{|c|}{$\begin{array}{l}\text { Evening work } \\
(\mathrm{N}=482) \\
(16.8 \%)\end{array}$} & \multicolumn{3}{|c|}{$\begin{array}{l}\text { Night work } \\
(\mathrm{N}=124) \\
(4.3 \%)\end{array}$} & \multicolumn{3}{|c|}{$\begin{array}{l}\text { Two-shift work } \\
\text { without night work } \\
(\mathrm{N}=474)(16.5 \%)\end{array}$} & \multicolumn{3}{|c|}{$\begin{array}{l}\text { Two- and three-shift } \\
\text { work with night work } \\
(\mathrm{N}=307)(10.7 \%)\end{array}$} & \multicolumn{3}{|c|}{$\begin{array}{c}\text { Total } \\
(\mathrm{N}=2870) \\
(100 \%)\end{array}$} \\
\hline & $\mathrm{N}$ & Mean & $\%$ & $\mathrm{~N}$ & Mean & $\%$ & $N$ & Mean & $\%$ & $N$ & Mean & n $\%$ & $\mathrm{~N}$ & Mean & $\%$ & N & Mean & $\%$ \\
\hline \multicolumn{19}{|l|}{ Cardiovascular risk factors } \\
\hline Prevalent hypertension & 85 & . & 5.7 & 31 & . & 6.4 & 6 & $\cdot$ & 4.8 & 28 & . & 5.9 & 19 & . & 6.2 & 169 & . & 5.9 \\
\hline Prevalent diabetes & 42 & . & 2.8 & 15 & . & 3.1 & 3 & . & 2.4 & 13 & . & 2.7 & 7 & . & 2.3 & 80 & . & 2.8 \\
\hline \multicolumn{19}{|l|}{ Smoking } \\
\hline Never smoker & 525 & . & 35.9 & 132 & . & 27.8 & 33 & . & 27.0 & 186 & . & 40.0 & 84 & . & 27.9 & 960 & . & 34.0 \\
\hline Ex-smoker & 271 & . & 18.5 & 80 & . & 16.9 & 17 & . & 13.9 & 86 & . & 18.5 & 72 & . & 23.9 & 526 & . & 18.6 \\
\hline Smoker (current) & 668 & . & 45.6 & 262 & . & 55.3 & 72 & . & 59.0 & 193 & . & 41.5 & 145 & . & 48.2 & 1340 & . & 47.4 \\
\hline Obesity (BMI $\geq 25$ ) & 516 & . & 37.3 & 252 & . & 43.6 & 65 & . & 44.4 & 160 & . & 36.4 & 111 & . & 38.4 & 1034 & . & 38.7 \\
\hline \multicolumn{19}{|l|}{ Physical activity } \\
\hline High & 66 & . & 4.5 & 24 & . & 5.0 & 5 & . & 4.2 & 24 & . & 5.1 & 28 & . & 9.2 & 147 & . & 5.2 \\
\hline Moderate & 463 & . & 31.5 & 157 & . & 32.8 & 49 & . & 41.2 & 168 & . & 35.7 & 102 & . & 33.6 & 939 & . & 33.1 \\
\hline Light & 821 & . & 55.9 & 250 & . & 52.3 & 52 & . & 43.7 & 239 & $\cdot$ & 50.9 & 147 & . & 48.4 & 1509 & . & 53.1 \\
\hline Physically inactive & 119 & . & 8.1 & 47 & . & 9.8 & 13 & . & 10.9 & 39 & . & 8.3 & 27 & . & 8.9 & 245 & . & 8.6 \\
\hline $\begin{array}{l}\text { Fruit and vegetables less than } \\
\text { once a day }\end{array}$ & 341 & . & 23.2 & 117 & . & 24.6 & 28 & . & 23.1 & 90 & . & 19.2 & 74 & . & 24.3 & 650 & . & 22.9 \\
\hline \multicolumn{19}{|l|}{ Covariates } \\
\hline Age in years & 1483 & 35.1 & . & 482 & 36.6 & . & 124 & 36.3 & . & 474 & 33.6 & & 307 & 33.6 & . & 2870 & 35.0 & \\
\hline Gender (women) & 1421 & . & 95.8 & 452 & · & 93.8 & 118 & . & 95.2 & 453 & . & 95.6 & 287 & . & 93.5 & 2731 & . & 95.2 \\
\hline Social and health care education & 1031 & . & 69.5 & 314 & . & 65.1 & 51 & . & 41.1 & 261 & . & 55.1 & 123 & . & 40.1 & 1780 & . & 62.0 \\
\hline \multicolumn{19}{|c|}{ Cohabitation status } \\
\hline Living with parents, no children & 100 & . & 6.9 & 27 & . & 5.7 & 4 & . & 3.3 & 42 & . & 9.1 & 21 & . & 7.0 & 194 & . & 6.9 \\
\hline Living with parents, children & 31 & . & 2.1 & 9 & . & 1.9 & 2 & . & 1.6 & 4 & . & 0.9 & 5 & . & 1.7 & 51 & . & 1.8 \\
\hline Living with partner, no children & 394 & . & 27.0 & 143 & . & 30.2 & 26 & . & 21.3 & 118 & . & 25.4 & 106 & . & 35.2 & 787 & . & 27.9 \\
\hline Living with partner, children & 642 & . & 44.1 & 172 & . & 36.3 & 69 & . & 56.6 & 198 & . & 42.7 & 102 & . & 33.9 & 1,183 & . & 42.0 \\
\hline Living alone, no children & 143 & . & 9.8 & 89 & . & 18.8 & 12 & . & 9.8 & 73 & . & 15.7 & 40 & . & 13.3 & 357 & . & 12.7 \\
\hline Living alone, children & 147 & $\cdot$ & 10.1 & 34 & . & 7.2 & 9 & $\cdot$ & 7.4 & 29 & . & 6.3 & 27 & . & 9.0 & 246 & . & 8.7 \\
\hline Self-efficacy (points) & 1471 & 66.4 & & 478 & 68.3 & . & 121 & 69.3 & . & 467 & 68.0 & . & 307 & 68.8 & . & 2844 & 67.4 & \\
\hline \multicolumn{19}{|l|}{ Father's occupation } \\
\hline Father did not live in the home & 104 & . & 7.5 & 40 & . & 8.9 & 12 & . & 10.1 & 34 & . & 7.7 & 21 & . & 7.2 & 211 & . & 7.8 \\
\hline Unemployed & 57 & . & 4.1 & 16 & . & 3.5 & 12 & . & 10.1 & 13 & . & 2.9 & 9 & . & 3.1 & 107 & . & 4.0 \\
\hline (Un)skilled worker & 690 & . & 49.7 & 214 & . & 47.5 & 55 & . & 46.2 & 201 & . & 45.4 & 140 & . & 48.1 & 1300 & . & 48.3 \\
\hline White-collar worker & 81 & . & 5.8 & 31 & . & 6.9 & 7 & . & 5.9 & 33 & . & 7.4 & 21 & . & 7.2 & 173 & . & 6.4 \\
\hline Executive & 161 & . & 11.6 & 62 & . & 13.7 & 10 & . & 8.4 & 54 & . & 12.2 & 49 & . & 16.8 & 336 & . & 12.5 \\
\hline Self-employed & 296 & . & 21.3 & 88 & . & 19.5 & 23 & . & 19.3 & 108 & . & 24.4 & 51 & . & 17.5 & 566 & . & 21.0 \\
\hline \multicolumn{19}{|l|}{ Years of school attendance } \\
\hline $7-9$ years & 279 & . & 18.9 & 97 & . & 20.2 & 28 & . & 22.8 & 76 & . & 16.1 & 55 & . & 17.9 & 535 & . & 18.7 \\
\hline $10-11$ years & 736 & . & 49.8 & 224 & . & 46.7 & 59 & . & 48.0 & 248 & . & 52.4 & 147 & . & 47.9 & 1414 & . & 49.4 \\
\hline High school or similar & 312 & . & 21.1 & 113 & . & 23.5 & 23 & . & 18.7 & 119 & . & 25.2 & 81 & . & 26.4 & 648 & . & 22.6 \\
\hline Other & 152 & . & 10.3 & 46 & . & 9.6 & 13 & . & 10.6 & 30 & . & 6.3 & 24 & . & 7.8 & 265 & . & 9.3 \\
\hline $\begin{array}{l}\text { Former experience in the } \\
\text { eldercare sector (yes) }\end{array}$ & 640 & . & 43.2 & 218 & . & 45.2 & 68 & . & 54.8 & 225 & . & 47.5 & 148 & . & 48.2 & 1299 & . & 45.3 \\
\hline
\end{tabular}

When sociodemographic factors and general selfefficacy were adjusted for, current smoking at baseline was associated with fixed evening work (OR 1.56, 95\% CI 1.21-2.02) and fixed night work (OR 1.64, 95\% CI 1.04-2.56). Being an ex-smoker was significantly associated with two- or three-shift work including night work (OR 1.85, 95\% CI 1.28-2.68). The association between the latter type of shift and current smoking was only of borderline significance (OR 1.37, 95\% CI 1.00-1.87). All of the other associations between risk factors of CVD and variants of the work schedules became nonsignificant in the adjusted analyses.

\section{Discussion}

Our results show that, in the unadjusted analyses, obesity, degree of leisure-time physical activity, and smoking status at baseline were associated with one or several variants of shift work at follow-up. When a range of possible confounders was controlled for, only smoking status at baseline was significantly associated with future work schedule. Fixed evening or night work was associated with being a smoker, and two- or three-shift work including night work was associated with being an ex-smoker. The estimates of the association between 
Table 2. Association between cardiovascular risk factors at baseline and the work schedule 1 year after formal education is finished. The adjusted estimates have been controlled for age, gender, education, cohabitation, general self-efficacy, father's occupation, years of school attendance, and former experience in the eldercare sector. (BMI = body mass index)

\begin{tabular}{|c|c|c|c|c|c|c|c|c|}
\hline \multirow[t]{2}{*}{ Cardiovascular risk factors } & \multicolumn{2}{|c|}{$\begin{array}{c}\text { Fixed } \\
\text { evening work }\end{array}$} & \multicolumn{2}{|c|}{$\begin{array}{l}\text { Fixed } \\
\text { night work }\end{array}$} & \multicolumn{2}{|c|}{$\begin{array}{l}\text { Two-shift work } \\
\text { without night work }\end{array}$} & \multicolumn{2}{|c|}{$\begin{array}{l}\text { Two- or three-shift work } \\
\text { with night work }\end{array}$} \\
\hline & $\mathrm{OR}$ & $95 \% \mathrm{Cl}$ & $\mathrm{OR}$ & $95 \% \mathrm{Cl}$ & $\mathrm{OR}$ & $95 \% \mathrm{Cl}$ & $\mathrm{OR}$ & $95 \% \mathrm{Cl}$ \\
\hline \multicolumn{9}{|l|}{ Unadjusted } \\
\hline Prevalent hypertension & 1.13 & $0.74-1.73$ & 0.84 & $0.36-1.96$ & 1.03 & $0.67-1.60$ & 1.09 & $0.65-1.81$ \\
\hline Prevalent diabetes & 1.10 & $0.61-2.01$ & 0.85 & $0.26-2.79$ & 0.97 & $0.52-1.82$ & 0.80 & $0.36-1.80$ \\
\hline \multicolumn{9}{|l|}{ Smoking } \\
\hline Never smoker & 1.00 & .. & 1.00 & .. & 1.00 & .. & 1.00 & .. \\
\hline Ex-smoker & 1.17 & $0.86-1.61$ & 1.00 & $0.55-1.82$ & 0.90 & $0.67-1.20$ & 1.66 & $1.17-2.35$ \\
\hline Smoker (current) & 1.56 & $1.23-1.98$ & 1.72 & $1.12-2.63$ & 0.82 & $0.65-1.03$ & 1.36 & $1.01-1.82$ \\
\hline Obesity (BMI $\geq 25$ ) & 1.30 & $1.05-1.61$ & 1.34 & $0.92-1.96$ & 0.96 & $0.77-1.20$ & 1.05 & $0.81-1.36$ \\
\hline \multicolumn{9}{|l|}{ Physical activity } \\
\hline High & 1.00 & .. & 1.00 & .. & 1.00 & ... & 1.00 & .. \\
\hline Moderate & 0.93 & $0.57-1.54$ & 1.40 & $0.54-3.63$ & 1.00 & $0.61-1.64$ & 0.52 & $0.32-0.85$ \\
\hline Light & 0.84 & $0.51-1.36$ & 0.84 & $0.32-2.17$ & 0.80 & $0.49-1.31$ & 0.42 & $0.26-0.68$ \\
\hline Physically inactive & 1.09 & $0.61-1.93$ & 1.44 & $0.49-4.22$ & 0.90 & $0.50-1.63$ & 0.54 & $0.29-0.98$ \\
\hline Fruit and vegetables less than once a day & 1.08 & $0.85-1.38$ & 1.00 & $0.64-1.55$ & 0.79 & $0.61-1.02$ & 1.07 & $0.80-1.42$ \\
\hline \multicolumn{9}{|l|}{ Adjusted } \\
\hline Prevalent hypertension & 1.04 & $0.66-1.63$ & 0.70 & $0.27-1.82$ & 1.26 & $0.79-2.02$ & 1.18 & $0.68-2.05$ \\
\hline Prevalent diabetes & 0.88 & $0.46-1.70$ & 0.98 & $0.29-3.31$ & 0.95 & $0.47-1.90$ & 0.74 & $0.30-1.80$ \\
\hline \multicolumn{9}{|l|}{ Smoking } \\
\hline Never smoker & 1.00 &.. & 1.00 & .. & 1.00 & .. & 1.00 & .. \\
\hline Ex-smoker & 1.21 & $0.87-1.70$ & 0.85 & $0.44-1.61$ & 0.94 & $0.68-1.29$ & 1.85 & $1.28-2.68$ \\
\hline Smoker (current) & 1.56 & $1.21-2.02$ & 1.64 & $1.04-2.56$ & 0.82 & $0.64-1.06$ & 1.37 & $1.00-1.87$ \\
\hline Obesity (BMI $\geq 25$ ) & 1.25 & $0.99-1.57$ & 1.30 & $0.86-1.95$ & 1.04 & $0.82-1.33$ & 1.25 & $0.95-1.66$ \\
\hline \multicolumn{9}{|l|}{ Physical activity } \\
\hline High & 1.00 & .. & 1.00 & .. & 1.00 & .. & 1.00 & .. \\
\hline Moderate & 0.92 & $0.54-1.56$ & 1.20 & $0.45-3.23$ & 1.03 & $0.61-1.75$ & 0.67 & $0.39-1.16$ \\
\hline Light & 0.90 & $0.54-1.52$ & 0.73 & $0.27-1.96$ & 0.89 & $0.53-1.50$ & 0.63 & $0.37-1.08$ \\
\hline Physically inactive & 1.20 & $0.65-2.20$ & 1.50 & $0.50-4.56$ & 0.96 & $0.51-1.80$ & 0.80 & $0.41-1.55$ \\
\hline Fruit and vegetables less than once a day & 1.10 & $0.84-1.42$ & 1.15 & $0.71-1.87$ & 0.80 & $0.60-1.05$ & 1.20 & $0.88-1.64$ \\
\hline
\end{tabular}

obesity and fixed evening work and fixed night work remained the same size in the adjusted model (about 1.3), but then the confidence intervals included unity. Our results indicate that a distinction between fixed "odd" workhours and alternating shift work including night work may be relevant as regards primary selection. Our results also show that there is a selection effect that could not be explained by differences in sociodemographic factors and self-efficacy.

Our results are in accordance with the finding of van Amelsvoort et al (19). In their study, shift work was defined as working in an alternating work schedule including night work. In their study, smokers at baseline worked more often as shift workers (OR 2.1, our own calculation). In addition former smoking was associated with increased odds for shift work (OR 1.8, our own calculation). The authors also found the mean BMI to differ significantly between day workers and shift workers; however, no possible confounders were included. Also in our study, obesity was significantly associated with fixed evening work, but this association disappeared in the adjusted analyses. Our results were in contrast to the results of Knutsson \& Åkerstedt (23). This difference could at least partially be ascribed to differences in the study population (the latter included male blue-collar workers applying for a job in a paper mill and a machine manufacturing plant).

Yet our results cannot necessarily be interpreted as causal relationships between current or former smoking at baseline and future work schedule. Instead of being the causal reason for choosing certain work schedules at follow-up, being a smoker at baseline may have been causally related to other underlying individual, social, and sociodemographic factors. Controlling for sociodemographic factors and general self-efficacy did not change the conclusions of our study as regards smoking. Still, we hypothesized that the association between smoking status and shift work was confounded by one or several unmeasured underlying factors. Such unknown confounding factors could explain the statistical association between baseline smoking and future work schedule. These confounders are interesting when the factors that causally predict future shift work are investigated. However, when the focus is on the detrimental effects 
of shift work, baseline differences have to be controlled regardless of their role in a causal chain.

It is surprising that (known) hypertension and diabetes at baseline were not associated with lower odds for different variants of shift work at follow-up. This result showed that there must be other, nonhealth-related factors that more strongly affect the choice of work schedule. In the eldercare sector, worktasks vary during the day, evening, and night. Therefore, the workers' individual preferences may lead to a choice of (a job implying certain) workhours wholly or partly because of the physical and psychological work demands at certain times of the day. For example, it has been shown that work conflicts and low control are more prevalent among female shift workers than among day workers (28); this difference may be a reason for a preference for day work. In addition, as we saw in our study, the family situation (living alone or with a partner or children) may differ between participants with different work schedules (table 1). This finding is in accordance with the results of a Dutch study in which work-family conflicts and too little leisure time were common incentives for leaving shift work (29).

Finally, the current situation in the labor market may influence the selection process. Thus, when the unemployment rate is rising, demanding work conditions (eg, "nonpreferred" workhours) may be endured to a greater extent because of the risk of unemployment. The opposite is the case when the unemployment rate is decreasing $(1,11)$. These occupational and other nonhealth-related factors may also affect the degree to which the results of our study can be generalized to other occupations and societies now and in the future. The current situation in the Danish labor market is characterized by a high employment rate with a relative abundance of vacant jobs available for the job-seeking group of social and health care workers. We therefore expect our results to reflect the self-selection mechanisms of the individual worker. On the other hand, in occupations or periods with high unemployment, employers may act as "gatekeepers into the labor market" to a higher extent and thereby perform their own selection of workers into jobs with either day or nonday work. Social stigmatization of smokers or obese people could play a role in both self-selection and gatekeeper selection. Furthermore, the distribution of smoking in the target population would be likely to influence the degree of selection into different work schedules, as well as the demand for day and shift workers at that given time and place. In our study of a mostly female population, none of the included covariates explained the association between smoking at baseline and work schedule at follow-up, and the mechanisms underlying this association are therefore unknown. Therefore, the generalizability of our results is hard to determine.
One limitation of our study was the high dropout rate between the baseline and follow-up, and we showed that there were significant associations between risk factors for CVD and the risk of dropout from the study. Whether this difference in the risk of dropout compromises the internal validity of our study depends on the extent to which the association between cardiovascular risk factors and future choice of work schedule differs between the participants and dropouts. We hypothesized that there is an association between dropout from the eldercare or hospital sector and participation in the study since dropout from the sector might have affected the participants' perception of the study's relevance. Although we have no way of determining this possibility, it seems evident that there is a close connection between a range of lifestyle-related factors and dropout from the study and maybe also dropout from social and health care work.

Differential misclassification could have had an impact on the results since $31 \%$ of the study population changed jobs during their first year within the eldercare sector. Moreover, the participants with shift work at follow-up (especially fixed night work or two or three shifts including night work) were more likely to have changed jobs during the preceding 12 months than day workers were. Restricting the analysis to the subgroup that did not change jobs during the last 12 months did not, however, change the conclusions of the study, although, in these analyses, the odds ratio for two- or three-shift work among the smokers now differed from unity.

We conclude that smoking status cannot be regarded only as a mediating factor between some variants of shift work and CVD; instead it must also be analyzed as a confounder. However, controlling for smoking status probably yields conservative estimates of the excess risk of CVD associated with fixed evening work, fixed night work, or two or three shifts including night work since behavioral changes as a consequence of shift work are also likely to occur (21). Future research should aim at differentiating between baseline differences (confounding) and behavioral changes (mediation) and, furthermore, focus on elucidating the dissimilarities in the work content and work environment of day and shift workers. These other factors could play a role in the causal chain between shift work and CVD, apart from a disruption of the circadian rhythm.

\section{Acknowledgments}

The study was supported by a 3-year grant from the Danish parliament.

We wish to thank Bente Schibye, Jette Nygaard Jensen, and Hanne Giver for their contribution to the development of the study design and the data collection. 


\section{References}

1. Bøggild H. Shift work and heart disease. Epidemiological and risk factor aspects [dissertation]. Aarhus (Denmark): Centre for Working time Research, Department of Occupational Medicine, Aalborg Regional Hospital \& Faculty of Health Sciences, University of Aarhus; 2000.

2. Bøggild H, Knutsson A. Shift work, risk factors and cardiovascular disease [review]. Scand J Work Environ Health. 1999;25(2):85-99.

3. Knutsson A. Health disorders of shift workers [review]. Occup Med (Lond). 2003;53:103-108.

4. Knutsson A, Åkerstedt T, Jonsson BG, Orth-Gomer K. Increased risk of ischaemic heart disease in shift workers. Lancet. 1986;2:89-92.

5. Olsen O, Kristensen TS. Impact of work environment on cardiovascular diseases in Denmark. J Epidemiol Community Health. 1991;45:4-10.

6. Kristensen TS. Cardiovascular diseases and the work environment: a critical review of the epidemiologic literature on nonchemical factors [review]. Scand J Work Environ Health. 1989;15:165-79.

7. Steenland K, Fine L, Belkic K, Landsbergis P, Schnall P, Baker $\mathrm{D}$, et al. Research findings linking workplace factors to CVD outcomes [review]. Occup Med. 2000;15:7-68.

8. Tüchsen F, Hannerz H, Burr H. A 12 year prospective study of circulatory disease among Danish shift workers. Occup Environ Med. 2006;63:451-5.

9. Yadegarfar G, McNamee R. Shift work, confounding and death from ischaemic heart disease. Occup Environ Med. 2008;65:158-63.

10. Åkerstedt T, Knutsson A, Alfredsson L, Theorell T. Shift work and cardiovascular disease [review]. Scand J Work Environ Health. 1984;10:409-14.

11. Kivimäki M, Virtanen M, Elovainio M, Väänänen A, Keltikangas-Järvinen L, Vahtera J. Prevalent cardiovascular disease, risk factors and selection out of shift work. Scand J Work Environ Health. 2006;32(2):204-8.

12. Knutsson A. Shift work and coronary heart disease [review]. Scand J Soc Med Suppl. 1989;44:1-36.

13. Nabe-Nielsen K, Garde A, Jensen JN, Borg V, Høgh A. Arbejdstider i ældreplejen [Workhours in eldercare]. Copenhagen: The National Research Centre for the Working Environment; 2007. SOSU report, no 15.

14. Knutsson A, Nilsson T. Tobacco use and exposure to environmental tobacco smoke in relation to certain work characteristics. Scand J Soc Med. 1998;26:183-9.
15. Knutsson A, Åkerstedt T, Jonsson BG. Prevalence of risk factors for coronary artery disease among day and shift workers. Scand J Work Environ Health. 1988;14:317-21.

16. Oishi M, Suwazono Y, Sakata K, Okubo Y, Harada H, Kobayashi $\mathrm{E}$, et al. A longitudinal study on the relationship between shift work and the progression of hypertension in male Japanese workers. J Hypertens. 2005;23:2173-8.

17. Suwazono Y, Sakata K, Okubo Y, Harada H, Oishi M, Kobayashi E, et al. Long-term longitudinal study on the relationship between alternating shift work and the onset of diabetes mellitus in male Japanese workers. J Occup Environ Med. 2006;48:455-61.

18. Ghiasvand M, Heshmat R, Golpira R, Haghpanah V, Soleimani A, Shoushtarizadeh P, et al. Shift working and risk of lipid disorders: a cross-sectional study. Lipids Health Dis. 2006;5:9-.

19. van Amelsvoort LG, Schouten EG, Kok FJ. Impact of one year of shift work on cardiovascular disease risk factors. J Occup Environ Med. 2004;46:699-706.

20. van Amelsvoort LG, Jansen NW, Kant I. Smoking among shift workers: more than a confounding factor. Chronobiol Int. 2006;23:1105-13.

21. Knutsson A. Methodological aspects of shift-work research [review]. Chronobiol Int. 2004;21:1037-47.

22. Orth-Gomer K Cardiovascular disease-factors of importance in shift workers. Stockholm: Arbetarskyddsverket; 1985. Arbete och hälsa, 27. p 57-63.

23. Knutsson A, Akerstedt T. The healthy-worker effect: self-selection among Swedish shift workers. Work Stress. 1992;6:163-7.

24. Bandura A. Self-efficacy. In: Social foundation of thought and action. Englewood Cliffs (NJ): Prentice Hall Inc; 1986. p 390-453.

25. Bandura A. Self-efficacy: toward a unifying theory of behavioral change. Psychol Rev. 1977;84:191-215.

26. Walsh WB. Introduction: special section on self-efficacy, interests, and personality. J Career Assess. 2007;15:143-4.

27. Betz NE, Hackett G. Career self-efficacy theory: back to the future. J Career Assess. 2006;14:3-11.

28. Bøggild H, Burr H, Tüchsen F, Jeppesen HJ. Work environment of Danish shift and day workers. Scand J Work Environ Health. 2001;27(2):97-105.

29. van Amelsvoort LGPM, Jansen NWH, Swaen GMH, van den Brandt PA, Kant I. Direction of shift rotation among three-shift workers in relation to psychological health and work-family conflict. Scand J Work Environ Health. 2004;30(2):149-56.

Received for publication: 30 October 2007 